\title{
HOW THE HEAT TREATMENT INFLUENCES CHANGES OF DIMENSIONS OF STRUCTURAL COMPONENTS
}

UDC: $621.78: 621.823$

Original scientific paper

https://doi.org/10.18485/aeletters.2018.3.2.1

\author{
Martin Vicen ${ }^{1}$, Peter Fabian ${ }^{1}$, Jozef Bronček ${ }^{2}$, Mário Drbúl ${ }^{3}$ \\ ${ }^{1}$ University of Žilina, Department of Technological Engineering, Slovakia \\ ${ }^{2}$ University of Žilina, Department of Design and Mechanical Elements, Slovakia \\ ${ }^{3}$ University of Žilina, Department of Machining and Manufacturing Technlogies, Slovakia
}

\begin{abstract}
:
The stresses in structural components can appear due to different reasons: loading, manufacturing long-time operations, etc. One of the reasons for stresses appearance is the heat treatment to which components sometimes need to be subjected. Changes in the size and shape of products are manifestations in the heat treatment. Although those changes are undesirable, they cannot be completely avoided and/or eliminated. This article deals with the effect of the heat treatment on change of the size of bearing rings. The aim was to compare the dimensions before and after the heat treatment, to find out whether the changes are within tolerance ranges or if the additional processing of components would be necessary. Another aim was to monitor the effect of layout of bearing rings on dimensions change.
\end{abstract}

\section{ARTICLE HISTORY}

Received: 06.02.2018.

Accepted: 27.02.2018.

Available: 30.06 .2018

\section{KEYWORDS}

heat treatment, bearing rings, changing dimensions, specific volume, bearing steel

\section{INTRODUCTION}

Inducing of stress is the regular accompanying phenomenon of the heat treatment processes. Temperature gradient occurs during the heating or cooling (through the cross-section of the heattreated steel). Micro and macro-volumes of material solidly bonded at different time, exhibit different temperatures and thus a different volume (assuming the same microstructure). Therefore, formation of stress, originated in thermal processes, occurs. Temperature gradient is also a reason why the phase transformation does not occur at the same time but in a certain time sequence, which causes stress of structural origin $[1,2]$.

The reason of the structural stresses is change in specific volume of structural components during the phase transformation. Those changes, occurring in the microstructure, are manifested by a uniform change in the dimensions (deformation) of the heat treated articles. Deformation of the steel parts during quenching is shown in Fig.1, documenting the dependence of a specific volume of the ferrite-carbide mixture, martensite and austenite on the carbon content of the steel $[2,3]$.

Increasing the carbon volume in quenched object increases dimensions changing throughout the ferrite-carbide structure transformation to martensite. The increasing amount of retained austenite, mixed with martensite, has the opposite effect and could completely eliminate the effect of martensite on the change in steel parts dimensions during quenching. It is called quenching with minimal deformation $[3,4]$.

Increasing dimensions after quenching can be reduced by tempering. This is due to the change of tetragonal martensite to cubic, precipitation of carbides and the dissolution of retained austenite. The theoretical knowledge about the change of specific volume (change of dimensions) of the bearing rings, due to change of the structural components after the heat treatment process will be verified in the experimental part $[5,6]$. 


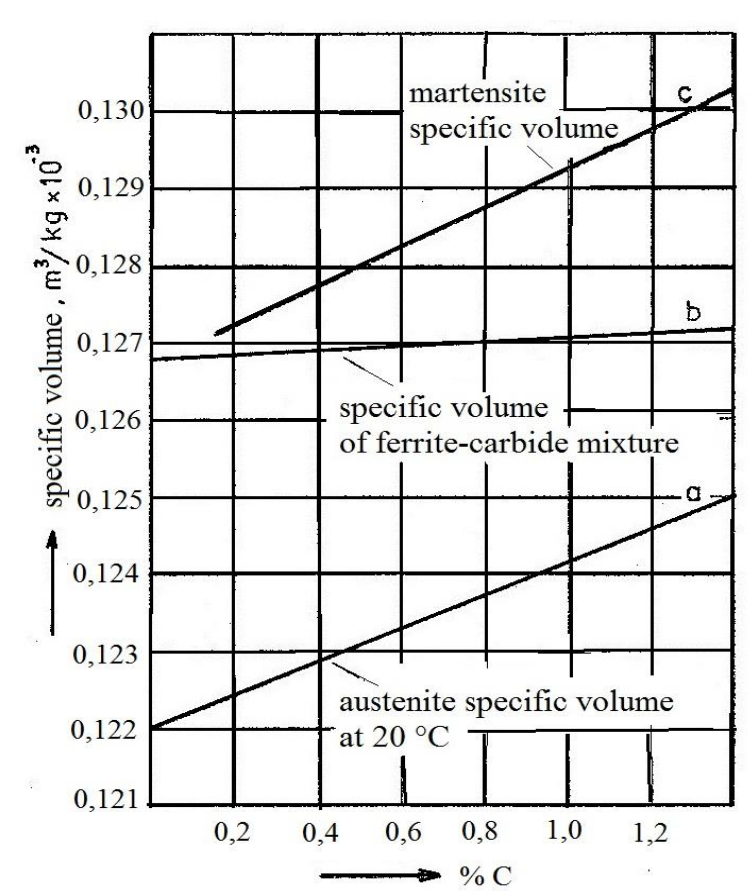

Fig. 1. The dependence of a specific volume of structural components on the carbon content [2]

\section{COMPONENT ANALYSIS}

The chosen component for the experiment was the inner bearing ring of the bearing wheel shown in Fig.2. The full component is assigned to group 2 on the safety scale. In this group, there are products that can put people at risk and need more attention. Therefore, the inner ring has importance its own position and dimensions. Any deviation of the dimension from the prescribed tolerance adversely affects the proper functioning of the entire component $[7,8]$.

\section{EXPERIMENTAL METHODOLOGY}

The aim of the experimental part was to monitor the change in the dimensions of randomly selected inner bearing rings before and after the heat treatment and to see if the change in dimensions is within the tolerances according to the standards. The rings have been made of $100 \mathrm{Cr} 6$ bearing steel with the chemical composition shown in Table 1, Fig.3 and Fig.4 shows the shape and dimensions of the inner bearing ring before and after the heat treatment.

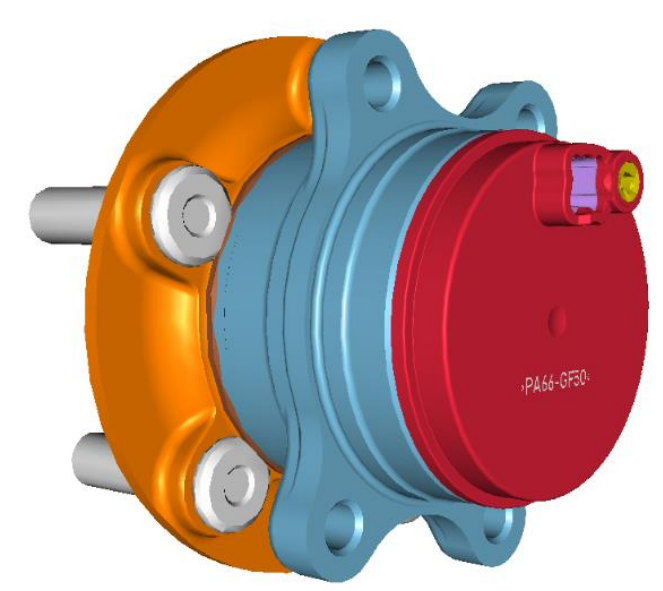

Fig. 2. Bearing wheel 3D model

Table 1. Chemical composition of the bearing ring

\begin{tabular}{|c|c|c|c|c|}
\hline Element & $\mathrm{C}$ & $\mathrm{Mn}$ & $\mathrm{Si}$ & $\mathrm{Cr}$ \\
\hline [wt. \%] & 1.0 & 0.4 & 0.25 & 1.45 \\
\hline Element & $\mathrm{P}$ & $\mathrm{S}$ & $\mathrm{Ni}$ & $\mathrm{Ni}+\mathrm{Cu}$ \\
\hline [wt. \%] & 0.027 & 0.03 & 0.03 & 0.5 \\
\hline
\end{tabular}

15 bearing rings have been selected to perform the experiment. Measurement of the size of the rings has been done after turning, just before being placed in the quenching baskets. The individual dimensions were measured using the Zeiss' 3D Coordinate Measurement Device (CMM) with a passive scanning probe that works with the Calypso software.

Annealing was not used before the heat treatment. Each bearing ring was numbered from 1 to 15 , and was located in quenching baskets according to the scheme shown in Fig.5.

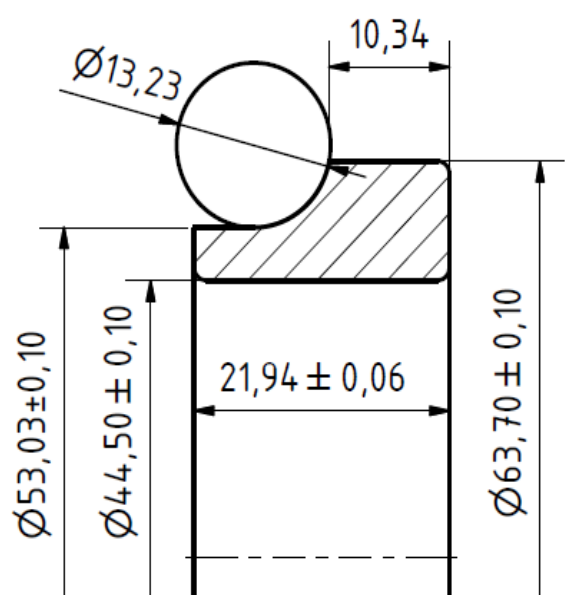

Fig. 3. Dimensions of the inner bearing ring - before heat treatment 


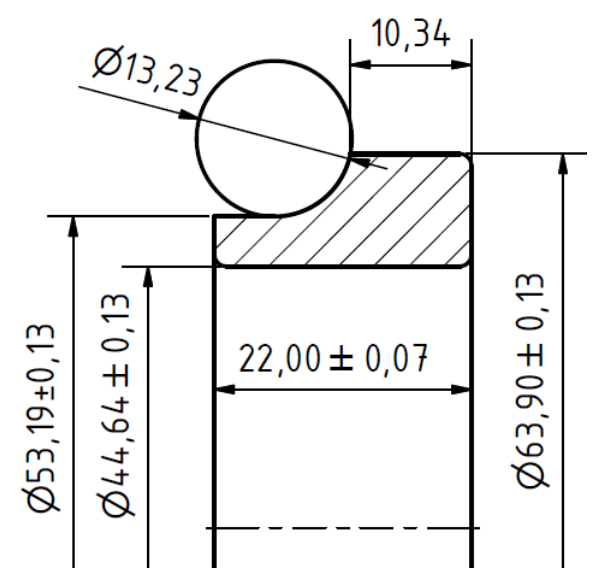

Fig. 4. Dimensions of the inner bearing ring - after heat treatment

The quenching of the bearing rings has been carried out in a Wllstroth salt-based Roller Hearth furnace system with a protective atmosphere (nitrogen gas, carbon, methanol and propane). The austenitising temperature was set on $860 \pm 5^{\circ} \mathrm{C}$.
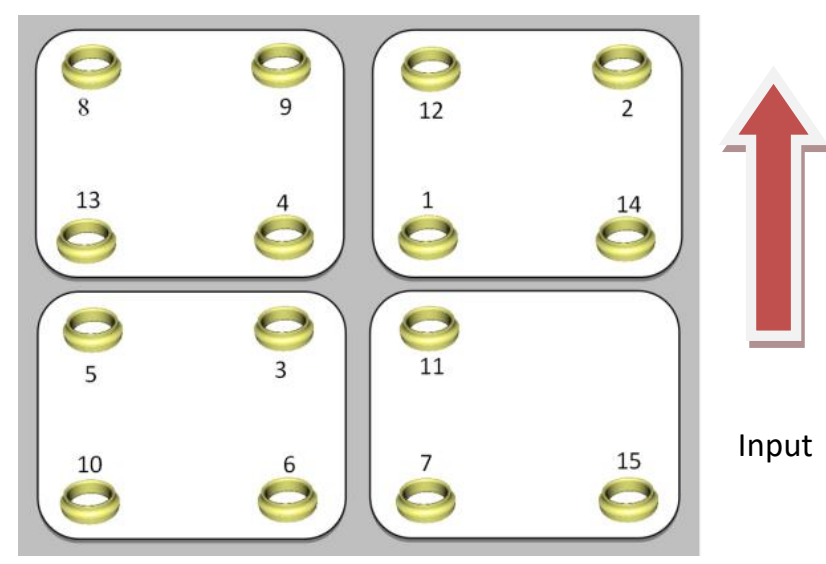

Fig. 5. Scheme of the rings layout in the quenching baskets

After keeping the temperature, cooling has been carried out in a salt bath at $220 \pm 20^{\circ} \mathrm{C}$ (salt type AS 135). Washing of rings has been performed before tempering to remove salt residues. The tempering has been carried out at temperature of $230^{\circ} \mathrm{C}$ for 300 minutes. After that, followed finishing as preserving (to avoid corrosion) and drying at which the finished quenching rings reached ambient temperature. After quenching, the dimensions of the rings were measured again and compared to the dimensions before the heat treatment. The measurement has been performed on the inner diameter of the ring, the outer ring diameters and height of the rings.

\section{RESULTS AND DISCUSSION}

Tables 2, 3 and 4 show the measured values of the fifteen selected bearing rings before and after the heat treatment and also values of the ring parts taken from the drawing.

Table 2. Dimensions of internal diameter rings

\begin{tabular}{|c|c|c|}
\hline & before HT & after HT \\
\hline Drawing values [mm] & $\varnothing 44.50 \pm 0.1$ & $\varnothing 44,64 \pm 0.13$ \\
\hline Ring number & \multicolumn{2}{|c|}{ Internal diameter [mm] } \\
\hline 1 & 44.53 & 44.58 \\
\hline 2 & 44.52 & 44.52 \\
\hline 3 & 44.54 & 44.58 \\
\hline 4 & 44.54 & 44.57 \\
\hline 5 & 44.52 & 44.56 \\
\hline 6 & 44.53 & 44.56 \\
\hline 7 & 44.51 & 44.54 \\
\hline 8 & 44.52 & 44.56 \\
\hline 9 & 44.53 & 44.56 \\
\hline 10 & 44.53 & 44.57 \\
\hline 11 & 44.53 & 44.59 \\
\hline 12 & 44.53 & 44.59 \\
\hline 13 & 44.53 & 44.57 \\
\hline 14 & 44.54 & 44.60 \\
\hline 15 & 44.53 & 44.54 \\
\hline
\end{tabular}

From the measured values it can be seen that the heat treatment has led to change of dimensions in each part and in all the observed rings.

Table 3. Dimensions of outer diameter rings

\begin{tabular}{|c|c|c|}
\hline & before HT & after HT \\
\hline Drawing values [mm] & $\varnothing 63.7 \pm 0.1$ & $\varnothing 63.9 \pm 0.13$ \\
\hline Ring number & \multicolumn{2}{|c|}{ Outer diameter [mm] } \\
\hline 1 & 63.72 & 63.97 \\
\hline 2 & 63.73 & 63.95 \\
\hline 3 & 63.72 & 63.97 \\
\hline 4 & 63.73 & 63.98 \\
\hline 5 & 63.73 & 63.99 \\
\hline 6 & 63.73 & 63.97 \\
\hline 7 & 63.73 & 63.98 \\
\hline 8 & 63.72 & 63.97 \\
\hline 9 & 63.73 & 63.99 \\
\hline 10 & 63.73 & 63.99 \\
\hline 11 & 63.73 & 63.98 \\
\hline 12 & 63.73 & 63.98 \\
\hline 13 & 63.74 & 63.99 \\
\hline 14 & 63.73 & 64.00 \\
\hline 15 & 63.73 & 63.93 \\
\hline
\end{tabular}


The amount of change was different for each ring. However the increase of dimensions has been observed in general point of view. The measured values also indicate that dimensional increments were in tolerance with drawing values for all the measured rings and all of their individual parts.

The observed increase of dimensions also corresponds to the theoretical knowledge presented in the introduction of this article.

The measured values of the individual bearing ring sizes are also shown by histograms that reflect deviations from the original dimensions more clearly (Fig.6, 7 and 8). Each of the histograms describes one size of the bearing ring. Histograms include dimensions before and after the heat treatment and also tolerance zone of the dimensions after the heat treatment.

Table 4. Dimensions of the rings height

\begin{tabular}{|c|c|c|}
\hline & before $\mathrm{HT}$ & after HT \\
\hline Drawing values [mm] & $21.94 \pm 0.06$ & $22 \pm 0.07$ \\
\hline Ring number & \multicolumn{2}{|c|}{ Ring height [mm] } \\
\hline 1 & 21.97 & 22.04 \\
\hline 2 & 21.98 & 22.06 \\
\hline 3 & 21.98 & 22.06 \\
\hline 4 & 21.98 & 22.06 \\
\hline 5 & 21.98 & 22.06 \\
\hline 6 & 21.98 & 22.06 \\
\hline 7 & 21.99 & 22.06 \\
\hline 8 & 21.98 & 22.06 \\
\hline 9 & 21.98 & 22.06 \\
\hline 10 & 21.98 & 22.05 \\
\hline 11 & 21.98 & 22.06 \\
\hline 12 & 21.98 & 22.06 \\
\hline 13 & 21.98 & 22.06 \\
\hline 14 & 21.98 & 22.06 \\
\hline 15 & 21.98 & 22.06 \\
\hline
\end{tabular}

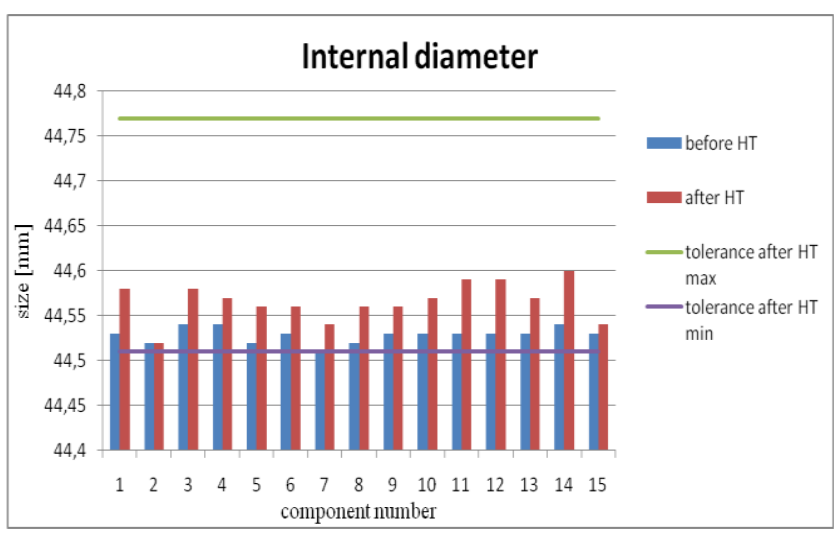

Fig. 6. Measured values of rings dimensions - internal diameter

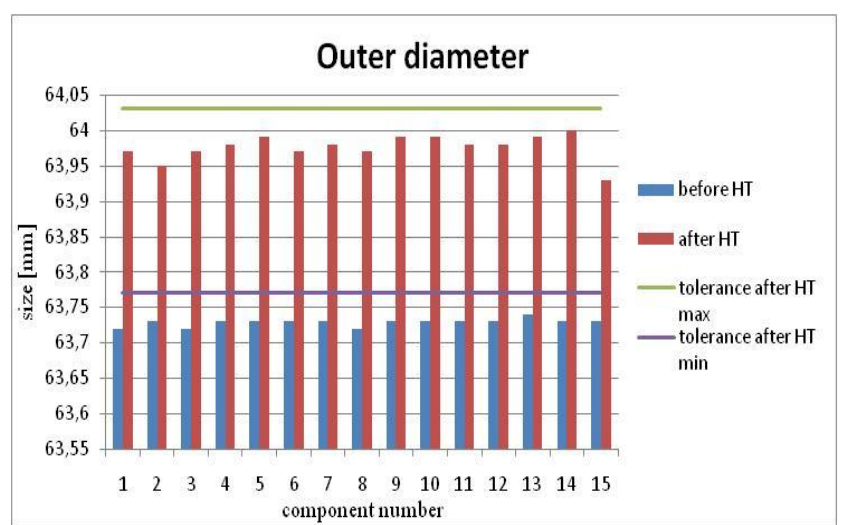

Fig. 7. Measured values of rings dimensions - outer diameter

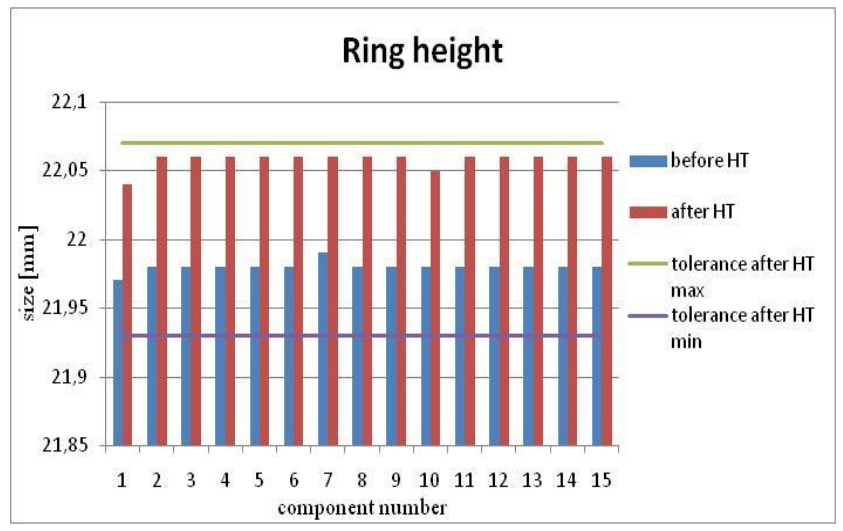

Fig. 8. Measured values of rings dimensions - the ring height

Average values of dimensions before and after the heat treatment are shown in Table 5. From these values, numerical and percentage changes of dimensions have been expressed.

Table 5. Numerical and percentage expression of dimensional changes after HT

\begin{tabular}{|c|c|c|c|c|}
\hline & \multicolumn{2}{|c|}{ Average values } & \multirow[b]{2}{*}{$\begin{array}{l}\text { Change } \\
\text { in } \mathrm{mm}\end{array}$} & \multirow[b]{2}{*}{$\begin{array}{c}\text { Change } \\
\text { in \% }\end{array}$} \\
\hline & $\begin{array}{c}\text { before } \\
\text { HT } \\
{[\mathrm{mm}]}\end{array}$ & $\begin{array}{c}\text { after } \\
\text { HT } \\
{[\mathrm{mm}]}\end{array}$ & & \\
\hline $\begin{array}{l}\text { Internal } \\
\text { diameter }\end{array}$ & 44.53 & 44.57 & 0.04 & 0.084 \\
\hline $\begin{array}{c}\text { Outer } \\
\text { diameter }\end{array}$ & 63.73 & 63.98 & 0.25 & 0.387 \\
\hline Ring height & 21.98 & 22.06 & 0.08 & 0.354 \\
\hline
\end{tabular}

\section{CONCLUSIONS}

The aim of the experiment was to monitor the change in dimensions of the inner bearing rings after the heat treatment. It can be concluded that:

$>$ increase of dimension was observed due to phase changes during the heat treatment for all chosen rings; 
the average increase of dimension after HT was $0.103 \mathrm{~mm}$, which represents $0.22 \%$ dimensional increase of bearing ring after the heat treatment, compared to the bulk state. The effects of volume changes can be partially compensated by appropriately chosen allowance before the heat treatment;

$>$ dimensional increments are in tolerance with the drawing values for all the measured bearing rings;

$>$ the impact of the dimensional changes of rings is not significant.

\section{REFERENCES}

[1] P. Fabian, J. Meško, R. Nikolić, Simulation of quenching process of steels creating complex carbides. FME Transactions, 45 (4), 2017: 510516.

\section{https://doi.org/10.5937/fmet1704510F}

[2] V. Zábavník, Technology of heat treatment. Rectorate of the Technical College in Košice, 1981, p.115.

[3] J. Jech, Roller bearing steels and their heat treatment. SNTL - Technical Literature Publishing, Prague, 1968, p.300.

[4] P. Jankejech, P. Fabian, J. Bronček, Y. Sahalapko, Influence of tempering on mechanical properties of induction bents below $540^{\circ} \mathrm{C}$. In Acta Mechanica et Automatica, 10 (2), 2016: 81-86.

https://doi.org/10.1515/ama-2016-0013

[5] B.Liščić, H. M. Tensi, L.C.F. Canale, G.E. Totten, Quenching theory and technology, CRC Press, 2010, p.691.

[6] R. Kohar, S. Hrcek, Dynamic Analysis of a Rolling Bearing Cage with Respect to the
Elastic Properties of the Cage for the Axial and Radial Load Cases. Communications, 3A (16), 2014: 74-81.

[7] B. Antoszewski, N. Radek, S. Tofil, J. Bronček, Dobór parametrów laserowej mikroobróbki powierzchniowej elementów panewek brązowych. Przeglad Elektrotechniczny, 93 (1), 2017: pp. 41-44. (In Polish).

https://doi.org/10.15199/48.2017.01.11

[8] M. Vicen, P. Fabian, J. Bronček, M. Drbul, Vplyv tepelného spracovania na zmeny rozmerov ložiskových krúžkov. Proceedings of the "23 $3^{\text {rd }}$ International Seminar of PhD Students SEMDOK 2018", 24-26 January 2018, Zuberec, Western Tatras, Slovakia, pp.177182. (In Slovak).

\section{ACKNOWLEDGMENT}

This work was designed as part of the project KEGA 042ŽU-4/2015 "Creation of a comprehensive educational - teaching material for the technology of a heat treatment of ferrous and non-ferrous materials" , part of the project 031ŽU-4/2016 "Implementation of Geometric product specifications (GPS) into the teaching process of engineering study programs and putting them into the technical practice" and project APVV SK-PL 2015-0008: "Research of the Operational Properties of the Laser Treated Electro Spark Coatings".

NOTE:

The shorter version of this research was presented at the "23" International Seminar of PhD Students SEMDOK 2018", 24-26 January 2018, Western Tatras, Zuberec, Slovakia. 